Revista Destaques Acadêmicos, Lajeado, v. 10, n. 1, 2018. ISSN 2176-3070

DOI: http://dx.doi.org/10.22410/issn.2176-3070.v10i1a2018.1769

http://www.univates.br/revistas

\title{
A ATUAÇÃO ESTATAL FRENTE AO DESENVOLVIMENTO DE MERCADO ALTERNATIVO DE ALIMENTOS: ANÁLISE COMPARATIVA ENTRE OS INCENTIVOS BRASILEIRO E EUROPEU AO MERCADO DE ALIMENTOS ORGÂNICOS
}

\author{
Amanda Jandrey Siebeneichler ${ }^{1}$
}

\begin{abstract}
Resumo: O Estado, enquanto sociedade política, tem se transformado à medida que assume novas funções para com seus indivíduos. Surgindo com o intuito de garantir dos direitos naturais e evoluindo para suprir necessidades mais pontuais do cidadão, ao aproximarmos a concepção de Estado à construção de novos mercados, especialmente no que tange à vida dos cidadãos, como o mercado de alimentos, evoca-se como questão problema qual é o papel do Estado na regulamentação destes mercados. Com a premissa de que o Estado deve garantir a segurança de seus indivíduos, com enfoque na regulamentação de mercados orgânicos, objetiva-se compreender a atuação do Estado quanto à regulamentação. $\mathrm{O}$ estudo tem caráter qualitativo, procurando estabelecer uma relação entre a evolução destes mercados e o papel ativo do Estado através de análise bibliográfica e documental, realizando um comparativo entre o mercado de alimentos orgânicos do Brasil e da Europa. Tem-se, portanto, o Estado, como um agente participante da construção destes mercados, procurando verificar se promove melhor qualidade de vida aos seus cidadãos, ao passo que envolve-se em um campo político mais complexo, no qual pode vir a se tornar um mero espectador. Resultados preliminares revelam que, no caso brasileiro, o Estado opera via marco regulatório dos orgânicos, o qual serve como parâmetro para os diferentes atores conduzirem suas atividades, diferentemente do modelo europeu, que opera especialmente via órgãos de regulamentação. Isto demonstra uma politização do consumo e a emergência de atores não-públicos que atuam neste campo, revelando a não atuação do Estado.
\end{abstract}

Palavras-chave: Alimentos Orgânicos. Estado. Política. Marco Regulatório.

Classificação JEL: Q18; Q57; Q58.

1 Graduanda do curso de Relações Internacionais pela Universidade do Vale do Taquari UNIVATES. 


\section{INTRODUÇÃO}

O desenvolvimento da temática em torno dos alimentos orgânicos, no Brasil, ainda é recente. No fim da década de 1970, houve um aumento de propostas "alternativas" como oposição ao padrão agrícola instituído até então, fazendo com que essa temática ganhasse força, expondo uma série de novos debates, embora seu surgimento não tenha sido acompanhado de um marco legal, tampouco de incentivo governamental ou privado. Assim como a Revolução Verde, que contrariando a mensagem que o nome passava, tinha como intuito aumentar expressivamente a produção ao invés de promover o desenvolvimento agrícola sustentável, a evolução da agricultura foi, em grande parte, movida pelo ganho monetário e pelo sustento das famílias rurais, enquanto que a preocupação com o meio ambiente foi deixada de lado (LEITE, 2013; ORMOND et al., 2002).

Percebeu-se, à medida que o uso crescente de insumos químicos passou a ser pauta de debates sobre a importância do cuidado ao meio ambiente, a necessidade de preocupar-se com o impacto que a utilização de tais insumos teria na vida dos consumidores. A temática da produção alternativa, que se caracteriza pela busca por modelos de produção de alimentos orientados a métodos sustentáveis, passou a ser debatida dentro dos Estados, entretanto, não foi pauta central das políticas discutidas durante as décadas de 1980 e 1990. Este fato deveu-se ao descaso com a preocupação ambiental, que, até o início dos anos 2000, era vista como custosa e sem importância para os negócios (RESENDE; RESENDE JÚNIOR, 2011).

Com o desenvolvimento do conceito de um modelo econômico sustentável, tem-se a ideia de que o Estado é o provedor dos instrumentos necessários para a modificação desse sistema produtivos, revelando-se tanto como um impedimento para essas mudanças, quanto percursor delas. Além disso, também tem importante papel social ao buscar realizar atividades que não prejudiquem a saúde da sociedade, como o incentivo a sistemas produtivos sustentáveis, onde a temática dos alimentos orgânicos se insere (BUAINAIN; BATALHA, 2007).

O papel do Estado como regulador e implementador insere-se nessa prática, tornando-se uma das questões principais deste assunto. Especificamente, busca-se analisar sua posição em relação à evolução desse tipo de prática, tentando compreender se ele é um agente propulsor ou se opta pela não intervenção no crescimento do mercado orgânico. Para isso, tendo como enfoque a análise comparativa entre o Brasil e a União Europeia (UE), o artigo busca apresentar uma reflexão teórica da evolução do sistema orgânico, seguida do histórico da formação contratualista do Estado, procurando analisar de que forma ambos os atores se articulam com relação à construção e ao desenvolvimento de um mercado efetivo de alimentos orgânicos. 


\section{EVOLUÇÃO DO SISTEMA DE PRODUÇÃO ORGÂNICO}

O surgimento da agricultura alternativa data entre os anos de 1925 e 1930, quando os estudos do inglês Albert Howard tinham como foco a importância da matéria orgânica, publicados no livro "Um Testamento Agrícola", em 1940. Ao passo que Howard procurava entender os benefícios da matéria orgânica para sistemas produtivos, na França, desenvolve-se a "agriculture bio-dynamique d'alimentação normale", tendo como produtos principais adubos verdes e resíduos vegetais. A Alemanha e o Japão também se tornam parte desse processo de desenvolvimento de agriculturas alternativas ao fazerem uso da agricultura biodinâmica e natural respectivamente.

O Brasil, entretanto, não tem registros concretos do desenvolvimento de sistemas produtivos alternativos. Foi possível, no entanto, estabelecer o surgimento de um movimento alternativo à medida que se criam organizações politicamente engajadas no desenvolvimento de uma sociedade mais democrática, visando a transformação social (BRANDENBURG, 2002; MADAIL et al., 2010). De acordo com Ormond et al. (2013), os métodos da agricultura alternativa eram completamente diferentes das práticas atuais, por não possuírem padrões ou regulamentações.

Dentre os diversos segmentos desenvolvidos pelo método de cultivo alternativo, encontra-se a agricultura orgânica, que, de acordo com a Instrução Normativa 007/99, proposta pelo Ministério da Agricultura, Pecuária e Abastecimento (MAPA), classifica

[...] sistema orgânico de produção agropecuária e industrial, é todo aquele em que se adotam tecnologias que otimizem o uso de recursos naturais e socioeconômicos, respeitando a integridade cultural e tendo por objetivo a auto-sustentação no tempo e no espaço, a maximização dos benefícios sociais, procurando minimizar dependência em energias não renováveis e a eliminação do emprego de agrotóxicos e outros insumos artificiais tóxicos, organismos geneticamente modificados-OGM/transgênicos ou radiações ionizantes em qualquer fase do processo de produção, armazenamento e de consumo, e entre os mesmos, privilegiando a preservação da saúde ambiental e humana, assegurando a transparência em todos os estágios da produção e da transformação (BRASIL, 1999).

O método de cultivo orgânico ganhou força entre a década de 1960 e 1970, com o surgimento de movimentos preocupados com o meio ambiente em favor de uma agricultura ecológica. Na Europa, surge o comércio dos primeiros produtos orgânicos, fortalecendo-se em meados de 1990 com o programa instituído pelo Council Regulation da CEE, que normalizou e padronizou a produção, processamento, comercialização e importação de produtos orgânicos de seus Estado-membros (ORMOND et al., 2013; MADAIL et al., 2010). 
O movimento da agricultura orgânica, no Brasil, tem um surgimento gradual na década de 1960, através do reconhecimento, por produtores e consumidores, dos problemas de saúde vinculados à utilização de fertilizantes químicos (MOREIRA et al., 2002, p. 300). Durante às duas décadas seguintes, 1970 e 1980, desenvolveram-se pequenos produtores orgânicos e organizações não-governamentais que visavam regulamentar e incentivar a produção e a comercialização de alimentos livres de insumos químicos. Os Encontros Brasileiros de Agricultura Alternativa (EBAAs) que ocorreram em 1981, 1984 e 1987 foram alguns dos principais impulsores do desenvolvimento da agricultura orgânica no Brasil (SANTOS, 2004; MADAIL et al., 2010).

A preocupação com o meio ambiente passou a ser pauta na agenda dos países a partir da Segunda Revolução agrícola, devido ao esgotamento de recursos causado pela Revolução Verde. A partir dos anos 1990, com a realização da Conferência das Nações Unidas sobre o Meio Ambiente e Desenvolvimento, conhecida como Eco-92, que ocorreu no Rio de Janeiro, o desejo e a preocupação com a reconciliação entre o desenvolvimento econômico e meio ambiente, fizeram com que os alimentos orgânicos ganhassem enfoque e possibilitassem a criação de marcos regulatórios. Esse processo auxiliou no desenvolvimento de novas técnicas agrícolas, resultando numa nova arquitetura dos mercados, permitindo que novos segmentos se tornassem cada vez mais fortes (NIEDERLE; ALMEIDA; VEZZANI, 2013).

Um número cada vez maior de organizações e de movimentos interessados na preservação do meio ambiente surgiu. Além das próprias ações do Estado, por meio da criação da instrução normativa que classifica os orgânicos, as ações tomadas por estas organizações também foram importantes para o desenvolvimento de um mercado alternativo de alimentos.

\section{O ESTADO}

As estruturas de poder do Estado que possuímos hoje são fruto de anos de debates teóricos acerca de qual a definição correta do Estado e qual é sua função. De John Locke a Immanuel Kant, passando por teóricos como Hobbes e Rousseau, deixou-se o Estado de Natureza, onde o homem, vivendo na incerteza, adere a um contrato social, adentrado à sociedade civil. Da teoria realista, que tem enfoque em conceitos como poder e conflitos, às teorias liberalista e idealista, que ressaltam a importância da democracia, da lei e sua legitimidade, abandonando o conflito para substituí-lo pela cooperação, esse contrato social evidencia os deveres do Estado para com os indivíduos que o compõem (ONUKI et al., 2010; SILVA, 2008; CHAUÍ, 2000; NETTO, 2007).

$\mathrm{O}$ conceito de Estado varia de acordo com a forma com que se analisa tal constituição. Apesar de ser considerado uma sociedade política, que seja, talvez, a mais sólida dos últimos séculos, o Estado, e todas as suas instituições, estão sujeitos à obediência de uma constituição, tal qual seus cidadãos 
(MIRANDA, 2003; OLIVEIRA, 2006, p. 545). Essa constituição era, inicialmente, uma série de pactos fundados entre múltiplas classes, constituindo uma série de privilégios em forma de jurisdição. Eram acordos de vontades, ou pactos de consentimentos, onde os indivíduos transferiam seus poderes a outro, seja um homem ou uma assembleia. De acordo com Oliveira (2006), o Estado pode ser entendido da seguinte forma:

Desde um viés sociológico, político ou constitucional, podendo ser entendido como uma corporação territorial dotada de um poder de mando originário; como comunidade de homem, fixada sobre um território, com potestade superior de ação, de mando e de coerção, ou ainda pessoa jurídica territorial soberana (OLIVEIRA, 2006, p. 545-546).

A primeira versão do Estado Moderno como uma organização de poder, surge, de acordo com Bobbio (1998), com a ascensão do absolutismo, em meados do século XVIII, ganhando força no início do século XIX (STRECK; MORAIS, 2001). Do estado absolutista ao Estado do Bem-Estar Social, cada uma dessas fases culminou na criação do Estado de Direito, que resultou em três formas distintas, reformulando o conceito de Estado. Os Estados Liberal e Social foram as primeiras formas do Estado de Direito. Cada uma delas tinha enfoque em uma temática diferente. Juntas, auxiliaram na formação do Estado Democrático de Direito, sendo este muito mais normativo que as versões anteriores. Unindo os problemas jurídicos propostos pelo Estado Liberal às questões sociais em pauta no Estado Social, resultou numa reestruturação do Estado, objetivando a igualdade e a transformação da sociedade através de leis, obedecendo a uma legislação, tudo em busca da garantia de condições mínimas de vida aos seus indivíduos (STRECK; MORAIS, 2001; MIRANDA, 2003).

A formação de uma sociedade democrática foi precedida por uma série de princípios que deveriam ser seguidos pelo Estado. Havia a necessidade de uma constituição que assegurasse os direitos básicos dos homens, bem como um sistema de direitos individuais e coletivos, que defendesse a liberdade, a autonomia do homem, a justiça e a solidariedade. Além disso, mecanismos que garantisse a segurança, a justiça social, a igualdade e a legalidade também se fizeram necessários (AQUINO et al., 2006; STRECK; MORAIS, 2001; NETTO, 2007). A partir da formação do Estado, surgem instituições jurídicas e sociais responsáveis por promoverem esses direitos considerados naturais ao ser humano.

Os direitos consolidados ao longo dessas variações do Estado surgiram lenta e gradativamente, através de uma série de revoluções e greves, com base nas necessidades dos indivíduos que compunham os Estados. Na transição do Estado Liberal para o Estado Social, de acordo com Moura (2009, p. 23), temse o discurso de cidadania de Thomas Marshall, em 1949. A análise trouxe conceitos como o civil, político e social para a construção da cidadania e, assim, 
dos direitos individuais. Com os direitos civis tendo surgido no século XVIII, a análise de Marshall aprofundou a questão dos direitos individuais, levando a uma declaração do Estado que assegurava o direito a vida, a liberdade, a igualdade, os direitos políticos, a segurança e o direito de resistência à prisão. A seguir, com o advento das Revoluções Industriais, apesar da proteção com relação ao Estado que asseguravam os direitos dos indivíduos, o mesmo não ocorria com relação ao novo sistema econômico (LEWANDOWSKI, 2003; KOERNER, 2003; STRECK; MORAIS, 2001).

Eclodiram revoluções com o objetivo de pressionarem o Estado a encontrar uma solução para as péssimas condições de vida na qual se encontravam os cidadãos, abandonando o papel de mero espectador, de acordo com Lewandowski (2003). Surgem, assim, os direitos econômicos, sociais e culturais de segunda geração, que estabeleciam direito ao trabalho, salário mínimo e duração máxima para a jornada de trabalho. Além disso, também fornecia amparo em casos como desemprego, doença, velhice, invalidez e morte; oferecia proteção a mulher e ao menor no trabalho, aposentadoria, acesso à educação e a bens de cultura, bem como o direito à criação de sindicatos e a greve (LEWANDOWSKI, 2003; FONSECA, 1978)

Com cada vez mais acesso à tecnologia e a ascensão do fenômeno da globalização, as guerras e as agressões ao meio ambiente, surgem direitos de solidariedade ou de fraternidade, considerados de terceira geração. Tais direitos legitimam os cuidados com o meio ambiente, a preservação da vida, ao direito a uma vida saudável e produtiva, a autodeterminação, a paz, ao desenvolvimento (...) (LEWANDOWSKI, 2003; BRITO, 2013)

Questões como direitos humanos, saúde e meio ambiente tornaramse parte da agenda política dos países a partir de uma série de conferências realizadas pelas Nações Unidas na tentativa de desenvolver uma opinião pública mundial, conforme Koerner (2003). Inicialmente, surgem no campo das Relações Internacionais através dos idealistas, alegando que a institucionalização e regras ajudaria a superar o estágio de conflito. Mais tarde, criam-se instituições comprometidas com as necessidades dos indivíduos, responsáveis por implementarem as políticas de responsabilidade do Estado. Sendo políticas, sociais ou econômicas, cada uma dessas instituições desempenha um papel fundamental na manutenção desse contrato social criado entre os indivíduos (ONUKI et al., 2010;).

A partir da formação do Estado, e de todas as suas organizações, nascem questionamentos acerca de sua legitimidade e se este Estado que se propôs a atender às necessidades de seus cidadãos, cumpre ou não o contrato social estabelecido. 


\section{MARCO REGULATÓRIO}

Sendo considerado ainda um mercado em ascensão, muitos países procuram desenvolver programas de incentivo à prática orgânica como forma de ampliar a produtividade e o consumo. Países como Alemanha e Estados Unidos promovem apoio governamental intenso com relação a este processo de produção. As primeiras normas privadas internacionais com relação ao processo produtivo de alimentos alternativos foram estabelecidas na década de 1980, pela International Federation for Organic Agriculture, apresentando normas "europeizadas" que não consideravam cenários com condições climáticas, tecnológicas e econômicas diferentes (BRASIL, 2001; BAUANIN; BATALHA, 2007; SANTOS et al., 2012).

Apesar da regulamentação promovida pela Federação Internacional dos Movimentos da Agricultura Orgânica (Ifoam), principal órgão mundial de assistência aos movimentos de agricultura orgânica, os países passaram a exigir a participação dos governos nos processos de regulamentação, especialmente com o surgimento de doenças e síndromes. Devido às exigências, em especial da Comunidade Europeia, a Comissão do Codex Alimentarius (CCA), órgão intergovernamental que objetiva proteger a saúde dos consumidores e garantir práticas leais no comércio de alimentos (CNCA, 2013, texto digital), no fim da década de 1990, estabeleceu diretrizes com relação à produção vegetal e ao processamento de alimentos orgânicos.

\subsection{União Europeia}

O mercado europeu de alimentos orgânicos é um dos que apresenta maior desenvolvimento, revelando uma estrutura rígida e progressista a fim de garantir a saúde e o bem-estar dos consumidores. A severidade com que a regulamentação é tratada revela a importância da qualidade do alimento. Desde julho de 2002, de acordo com Fonseca (2002, p. 290), a UE exige um sistema de rastreamento para importar carne bovina. Esse sistema permite saber o histórico do animal, estabelecendo se este se encontra de acordo ou não com as normas estabelecidas para a compra de alimentos orgânicos. A evolução deste mercado dentro da UE é evidente, considerando todos os esforços empregados tanto pelo governo, quanto pelas empresas privadas em prol da modificação do sistema produtivo.

O governo europeu tem desenvolvido programas e metas que forneçam subsídios a agricultores com a intenção de ampliar esse mercado (BUAINAIN; BATALHA, 2007; FONSECA, 2002). Os programas são postos em prática a partir de padrões, que variam conforme a necessidade e o desejo do público a ser contemplado por este. Eles assumem padrões como o voluntariado, que tem apoio direto do governo; o modelo privado, onde não há interferência do governo, ainda em estágio de desenvolvimento. Modelos cooperativos, como os que podem ser encontrados na Dinamarca e na Argentina, são processos entre 
a comunidade orgânica e o auxílio do governo (FONSECA, 2002, p. 272). Países como a Suíça desenvolveram programas para subsidiar novos produtores de orgânicos que não podem arcar com os custos da transição na produção, como pode ser visto no texto de Renaud e Lammerts Van Bueren (2016):

Bio Suisse, a Swiss certification body, has created a fund to address the price difference between organic and conventional seed. If a grower needs to use conventional seed because there is no comparable variety in organic form, the grower pays the difference in the cost of the seed into a fund that supports organic seed-breeding and multiplication, such as variety trials (RENAUD; LAMMERTS VAN BUEREN, 2016, p. 274).

A Dinamarca também possui um fundo de auxílio a grupos de produtores com o intuito de desenvolver e alavancar o mercado de orgânicos. Entretanto, é preciso ter em mente que nenhum sistema é perfeito. Mesmo na Europa, o desenvolvimento lento da agricultura orgânica é um fato. Como menciona, Brzezina et al. (2017, texto digital), para deixar de ser considerado apenas um nicho de mercado, a agricultura orgânica europeia ainda precisa vencer muitos desafios, como a sua convencionalização, um processo de apropriação de valores e práticas agroecológicos que são conduzidos nos mesmos moldes da agricultura convencional (NIEDERLE; ALMEIDA; VEZZANI, 2013).

\subsection{Brasil}

Como um país agroexportador, detentor de uma rica biodiversidade, investir no desenvolvimento econômico de caráter sustentável é, de certa forma, contemplar a abundância de matéria-prima que caracteriza o Brasil. A questão de um mercado agroecológico continua em expansão. Entretanto, modelo brasileiro de expansão agrícola alternativa não conta com o mesmo investimento e nem com o incentivo governamental de investirem em uma nova forma de produção, revelando grandes diferenças entre o Brasil e a UE no tocante à regulamentação dos orgânicos, apesar do empenho brasileiro em desenvolver um mercado alternativo de alimentos (VIEIRA, 2014; NIEDERLE; ALMEIDA; VEZZANI, 2013).

Em 2012, através do decreto 7.794, foi lançado a Política Nacional de Agroecologia e Produção Orgânica (Pnapo), responsável por destinar cerca de $\mathrm{R} \$ 2,9$ bilhões para incentivar a articulação de agentes públicos e privados em torno da agroecologia (SAMBUICHI et al., 2017). O PNAPO seria responsável pela construção de diretrizes importantes à questão da agroecologia. Deveria garantir a segurança e a soberania alimentar, reduzir a dependência em insumos externos, ou seja, aumentar relativamente à produção interna do país; o programa deveria, ainda, ampliar a participação social em ações e políticas voltadas para a construção de um mercado de alimentos orgânicos. Em tempo, deveria haver incentivo à abordagem da agroecologia e ampliar a 
inclusão e o acesso a produtos, processos e tecnologias próprios de um sistema agroecológico de produção (SIMONI, 2013).

Entretanto, os deveres do programa não foram cumpridos de todo, uma vez que o PNAPO não obteve a devida repercussão, já que o Programa Nacional de Fortalecimento da Agricultura Familiar (Pronaf) é muito mais conhecido, embora não forneça nenhum auxílio ao produtor de orgânicos. O PNAPO conseguiu inserir na agenda brasileira o debate sobre políticas públicas que tratem da agroecologia, mas não foi suficiente para fazer com que houvesse ações mais sólidas do governo brasileiro, delegando o esforço a agricultores, organizações e movimentos sociais articulados em prol desse sistema (CIAPO, 2013).

As ações do Estado se limitam a garantir que esse mercado exista, apesar de caber ao Ministério da Agricultura acompanhar, dar o devido credenciamento e fiscalizar os órgãos previamente cadastrados, tais certificadoras, ainda que passem por um processo de verificação conduzido pelo Instituto Nacional de Metrologia, Qualidade e Tecnologia (Inmetro), não garantem o nível de excelência do alimento e sim o selo (CI ORGÂNICOS, 2017, texto digital).

\section{CONCLUSÃO}

Considerando o mercado de alimentos orgânicos, seja no Brasil ou fora dele, como um mercado em ascensão, que carece de aperfeiçoamento e ainda tem muito a buscar para sua evolução, este comparativo revela que a atuação dos Estados está subjugada aos seus desejos. Muito embora possa ser possível perceber que o mercado europeu tem muito mais incentivo e apoia novos consumidores, não é cabível afirmar que o Brasil não investe em melhorias quanto aos mercados alternativos.

O que de fato, falta ao mercado de alimentos orgânicos brasileiro é uma estrutura sólida, que mantenha a qualidade do mercado, não viabilizando apenas ganhos econômicos. A estrutura apresentada pelo mercado de alimentos orgânicos dentro da Europa, revela-se um resultado da inter-relação entre políticas públicas propostas pelos Estados e o desenvolvimento social com o qual estes mercados são construídos (NIEDERLE; ALMEIDA; VEZZANI, 2013, p. 218). Entretanto, vale ressaltar que, mesmo com a atuação conjunta, o mercado orgânico europeu não é, ainda, o ideal.

É possível constatar, ao longo deste trabalho, uma intensa preocupação brasileira com grandes empresas, desfavorecendo assim, o papel de pequenos consumidores. Existe ainda, um baixo incentivo governamental à produção de alimentos alternativos, uma vez que o produtor é, de certa forma, induzido à produção convencional quando as empresas fornecem o que pode ser denominada de agricultura tóxica, que inclui uma série de elementos químicos que degradam o meio ambiente e fazer mal à saúde de quem produz e de quem consome. 
Dessa forma, o estado peca ao não cumprir o contrato social préestabelecido, não protegendo às necessidades de seu povo, e esse descaso é acentuado e evidenciado quando, por iniciativa governamental, incentivou-se a aprovação de uma medida provisória que facilita o registro e a utilização de agrotóxicos com potencial cancerígeno (FORMENTI, 2017, texto digital).

O papel do Estado é garantir o bem-estar da população e, desta forma, proporcionar uma alimentação mais segura aos seus indivíduos, garantindo o cumprimento do contrato social. Entretanto, ainda impera, em ambos os Estados, o viés econômico atrelado à produção orgânica. A produção de alimentos mais saudáveis tem mais a ver com o desenvolvimento econômico dos produtores que com a melhoria na qualidade de vida destes.

Tal percepção levanta uma série de questionamentos a cerca da formação deste mercado, reiterando a necessidade de compreender o papel do Estado para que se possam estabelecer quais as ações que se fazem necessárias. Além disso, também questiona as atitudes da população com relação ao uso dos agrotóxicos, quase suas ações e qual seu papel como indivíduo pertencente a um Estado. Embora o estudo se limite à análise bibliográfica, possibilita estudos mais aprofundados para a compreensão desta relação entre a formação destes mercados e o papel fundamental do Estado.

\section{REFERÊNCIAS}

AQUINO, Rubens S. L. de; FRANCO, Denise A. e LOPES, Oscar G. C.. História das sociedades: das sociedades modernas às sociedades atuais. Rio de Janeiro: Ao Livro Técnico. 2006

BOBBIO, Norberto. Dicionário de Política. Brasília: Editora Universidade de Brasília, 1998.

BRANDENBURG, Alfio. “Movimento Agroecológico: trajetória, contradições e perspectivas". Desenvolvimento e Meio Ambiente, n. 6, p. 11-28, 2002.

BRASIL. Instrução normativa no 007 de 17 de maio de 1999. Diário oficial da União, de 19 de maio de 1999, Seção 1, página 11.

BRITO, Rafaela S. Os princípios da fraternidade e da solidariedade como vetores na aplicabilidade do direito ambiental. In: CURY, M; CERQUEIRA, M. do R. F; PIERRE, L A. A;

FULAN, V. (Orgs.). Fraternidade como categoria jurídica. São Paulo: Cidade Nova, 2013. p. 169-180.

BRZENINA, Natalia; BIELY, Katharina; HELFGOTT, Ariella; KOPAINSKY, Birgit; VERVOOT, Joost; e MATHIJS, Erik. "Development of Organic Farming in Europe at the Crossroads: looking for the Way Foward throught System Archetypes Lenses". 
Sustainability, v. 9, n. 5, 2017. Disponível em: < http:/ /www.mdpi.com/20711050/9/5/821/htm> Acesso em 11 set. 2017.

BUAINAIN, Antônio M. e BATALHA, Mário O. (Coord.). Cadeia produtiva de produtos orgânicos. Brasilia: Ministério da Agricultura, Pecuária e Abastecimento: IICA, 2007. 108 p.

CI ORGÂNICOS - Centro de Inteligência em Orgânicos. Manual de Certificação de Produtos Orgânicos. Rio de Janeiro, 2017. Disponível em: <http:/ / www.organicsnet. com.br/certificacao/manual-certificacao/> Acesso em 22 set. 2017.

CIAPO - Câmara Interministerial de Agroecologia e Produção Orgânica. Plano Nacional de Agroecologia e Produção Orgânica - PLANAPO. Brasília, DF: MDS; CIAPO, 2013. Disponível em: <www.mda.gov.br/sitemda/sites/sitemda/files/user_ img_19/BrasilAgroecologico_Baixar.pdf>. Acesso em: 20 set. 2017

CNCA, Cabo Verde. Comissão Nacional do Codex Alimentarius: Manual de Procedimentos. 2013. Disponível em: < http: / / www.portaldoconhecimento.gov. cv/bitstream/10961/3833/1/Comiss \%C3\%A3o\%20Nacional\%20do\%20Codex $\% 20$ Alimentarius\%20-\%20Manual\%20de\%20Procedimentos.pdf> Acesso em 20 ago. 2017.

FONSECA, Maria F. “Certificação de Sistemas de Produção e Processamento de produtos Orgânicos de Origem Animal: História e Perspectivas". Cadernos de Ciência \& Tecnologia, v. 19, n. 2, p. 267-297, 2002.

FORMENTI, Lígia. "MP pode afrouxar regras para agrotóxicos". Estadão, São Paulo, 20 abr. 2017. Disponível em: <http:/ / economia.estadao.com.br/noticias/geral,mppode-afrouxar-regras-para-agrotoxicos,70001745113> Acesso em 20 set. 2017.

LEITE, Romeu M. “Dez anos de Regulamentação da Agricultura Orgânica, experiência de Sistema Participativo de Garantia, Avanços, Desafios e Oportunidades da Agroecologia e Produção Orgânica no Brasil", Planeta Orgânico, 2013. Disponível em: <http:/ / planetaorganico.com.br/site/wpcontent/uploads/2013/06/Dez_anos_ de_Regulamentacao_da_Agricultura_Organica.pdf>. Acesso em 20 ago. 2017.

LEWANDOWSKI, Enrique R. “A formação da Doutrina dos Direitos Fundamentais. Revista da Faculdade de Direitos da Universidade de São Paulo, v. 98 , p. 411-422, 200.

MADAIL, João Carlos M.; BELARMINO, Luiz C.; BINI, Dienice A. “Evolução da produção e mercado de produtos orgânicos no Brasil e no mundo". Revista Científica da Lajes, v. 3, 2010.

MIRANDA, Jorge. Teoria do Estado e da Constituição. Rio de Janeiro: Forense, 2003.

MOREIRA, Josiano C.; JACOB, Silvana C.; PERES, Frederico; LIMA, Jaime S.; MEYER, Armando; OLIVEIRA-SILVA, Jefferson J.; SARCINELLI, Paula N.; BATISTA, Darcilio F.; EGLER, Mariana; FARIA, Mauro V. C.; ARAÚJO, Alberto J.; KUBOTA, Alexandre H.; SOARES, Mônica de O.; ALVES, Sergio R.; MOURA, Cláudia M.; CURI, Rosane. "Avaliação Integrada do Impacto do Uso de Agrotóxicos sobre a Saúde Humana em 
uma Comunidade Agrícola de Nova Friburgo, RJ". Ciência \& Saúde Coletiva, v. 7, n. 2, p. 299-311, 2002.

MOURA, Aline B. “O Discurso da cidadania em Marshall: a influência do modelo clássico na teoria jurídica moderna”. JURISVOX, v. 10, p. 22-34, 2009.

NETTO, Adyr Garcia Ferreira. “Do Estado de Natureza ao governo Civil em John Locke". Revista de Direito Público, v. 2, n. 2, p. 75-90, 2007.

NIEDERLE, Paulo A.; ALMEIDA, Luciano e VEZZANI, Fabiane M. (Org.) Agroecologia: práticas, mercados e políticas para uma nova agricultura. Curitiba: Kairós, 2013. 393 p.

OLIVEIRA, Rúbia N. “Do Estado moderno ao Estado Constitucional - Algumas considerações". Revista Eletrônica Direito e Política, v. 1, n. 1, p. 542-560, 2006.

ONUKI, Janina; PINHEIRO, Letícia; e VIZENTINI, Paulo. O Brasil nas Instituições Internacionais. 2010.

ORMOND, José G. P.; DE PAULA, José R. L. F., e FAVEREST, Paulo. Agricultura orgânica: quando o passado é futuro. Rio de Janeiro: BNDES Setorial, 2002. 24p.

RENAUD, Erica N. C. e LAMMERTS VAN BUEREN, Edith T. "The meta-governance of organic seed regulation in the USA, European Union and Mexico". International Journal of Agricultural Resources, Governance and Ecology, v. 12, n. 3, p. 262-291, 2016.

RESENDE, Sebastião A. A. e RESENDE JÚNIOR, Joaquim C. “Cultivo Orgânico: origem, evolução e importância sócio econômica e ambiental". Enciclopédia Biosfera, v. 7, n. 13, p. 1119-1127, 2011.

SANTOS, José O.; SANTOS, Rosélia M. de S.; BORGES, Maria da G. B.; FERREIRA, Reginaldo T. F. V.; SALGADO, Alberto B. e SANTOS SEGUNDO, Ovídio A. "A Evolução da Agricultura Orgânica". Revista Brasileira de Gestão Ambiental, v. 6, n. 1, p. 35-41, 2012.

SAMBUICHI, Regina H. R.; SPÍNOLA, Paulo A. C.; MATTOS, Luciano M.; ÁVILA, Mário L.; MOURA, Iracema F., e SILVA, Ana P. M. Análise da Construção da Política nacional de Agroecologia e Produção orgânica no Brasil. Brasília: Instituto de Pesquisa Econômica Aplicada - Ipea, 2017.

SIMONI, Joana C. “O processo de construção da política nacional de agroecologia e produçao orgânica (PNAPO): diálogos e disputas no caminho da transição". In: Encontro de Geógrafos da América Latina, 2013, Lima. Anales del XIV Encuentro de Geógrafos de América Latina 2013 Perú., 2013.

STRECK, Lenio L. e MORAIS, Jose L. B. Ciência Política e Teoria do Estado. Editora

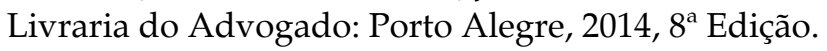

VIEIRA, Camila B. "Produtos Orgânicos no Brasil: interfaces de sua legislação".

Revista Espaço de Diálogo e Desconexão, v. 8, n. 2, 2014. 